\title{
Welcome to the 1985 MRS Fall Meeting
}

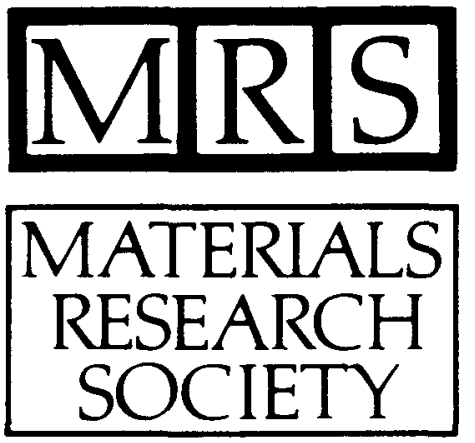

This year MRS sees two Fall Meetings.

In Strasbourg, France, the European Materials Research Society Fall Meeting runs from November 26 through 29 and focuses on Advanced Materials R \& D for Transport. Three symposia treating particular materials issues in the transportation industry will be held in the beautiful Council of Europe facility. To those of you finding this issue of the BULLETIN in your registration material in Strasbourg, welcome to the first Fall Meeting of the European MRS. You are participating in a forum specifically designed to enhance communication among materials researchers whose necessarily interdisciplinary approach requires such topically focused symposia. The symposia chairpersons and the local staff have in vested a large effort in planning the program and logistics of your meeting, and we are sure you will find this meeting most productive. We would also welcome your continued participation in the activities of E-MRS. You may obtain more information about the Society by contacting the headquarters at the Strasbourg address given in the front of this BULLETIN.

In Boston, the annual Fall Meeting convenes December 2 and runs through December 7. On behalf of the Materials Research Society, let me welcome participants arriving in Boston. Normally in describing our ever expanding meeting activities, strings of superlatives are necessary. This 1985 Fall Meeting is certainly no exception. As you see from your program, we have 20 topical symposia covering research at the forefront of their respective fields. We have the ever popular lunch time Symposium $X$ which offers the nonspecialist insight into advances in various materials areas. And, completing the list, we have a wholly new departure for MRS in Symposium $Y$, which delves in to the issues of materials education, a field which is clearly the precursor to the pursuit of all the work reported in our forums.

Taken together this program is the largest yet offered to MRS participants and comprises over 1,250 individual presentations. This is the first year we find MRS activities running in two hotels and are fortunate to have been able to take advantage of the Boston Marriott/Copley Place and the Westin Hotel which are so convenient to each other.

A great deal of planning is required to bring together a meeting such as this. First and foremost among those who have devoted their time and expertise to this task are the meeting chairs. These are John Baglin of IBM, David Biegelsen of Xerox, and John Fan of the MIT Lincoln Laboratory. The high quality of the program and its coordination can be attributed to the long hours invested by such talented individuals as these and we certainly owe them a debt of gratitude. Each symposium has likewise benefited from the technical excellence and diligence of their respective chairs. These scientists have formulated outstanding programs which will represent the latest, most incisive, advances in their fields by and to their broad interdisciplinary international groups of participants.

Once again the central objective of MRS for its meetings has been superbly fulfilled. Behind the scenes, much of the logistical support for this largest-ever meeting has been provided by the MRS Headquarters staff under the direction of Executive Director John Ballance. With the MRS Headquarters just entering its third year of existence, it has managed this gargantuan task with great success

In addition to the technical symposia, you will find that this year's Fall Meeting offers a substantially expanded program of short courses. The 14 courses, available on Friday and Saturday of the meeting, were assembled by L. Ralph Dawson, cochair of the MRS Education Committee. Also expanded this year is the MRS Equipment Show run for MRS by the American Institute of Physics. Over 100 booths will display the "implements of our profession" and I encourage all participants to visit the show which is open Tuesday through Thursday. Those attendees who are interested in employment opportunities may take advantage of the MRS Job Placement Center. The Center, which was well utilized the first time it was of fered last year, will again be handled for MRS by the AIP Placement
Service.

Let me also invite each participant to attend the Awards Ceremony on Monday, December 2 . At that time we will have the distinct privilege of presenting $15 \mathrm{graduate}$ student awards for outstanding papers presented at this meeting and to present the Von Hippel Award to John W. Cahn of NBS. Please join me in honoring our award recipients and in attending the reception which follows.

Beyond the events of the annual Fall Meeting, many more exciting MRS activities have taken place. The Education Committee has implemented the travel grant and speaker tour programs for Student Chapters. New local Sections and Student Chapters are forming, some of which will be chartered at the All-Society Plenary Session on Wednesday, December 4. The first MRS produced proceedings volumes rolled off the presses in 1985. You will find many of these displayed in the meeting registration area. And, Journal of Materials Research, the new MRS-owned, AIP published, comprehensive archival journal for our field, has been launched. Since this time last year, the number of full-time Headquarters staff has more than doubled, increasing from three to seven, in order to manage these expanded and new endeavors.

Going largely unnoticed, aside from the occasional note in the BULLETIN, is the year-round work of the II MRS commit tees. Much of the activity described above is initiated and overseen by these committees. Their function is vital to the health and vitality of the Society. During the Fall Meeting, the committees meet to formulate plans for the future and assess ongoing programs. These are individual MRS members contributing their talents to the Society's needs. I encourage any and all of you who would like to become involved in MRS and its future to express that interest to any official of MRS during or after the meeting.

In closing, let me wish you, our participants, whether in Boston or Strasbourg, a very productive and stimulating week and an enjoyable stay in our host city. 


\section{MRS CORPORATE AFFILIATES}

AG Associates

Air Products and Chemicals

ALCOA

Allied Corporation

American Microsystems, Inc.

AMOCO Corporation

Applied Materials

ARCO Metals Company

ARCO Solar, Inc.

AT\&T Bell Laboratories

AT\&T Technologies, Inc

Blake Industries, Inc.

Branson, IPC

Brimrose Corporation of America

Brush Wellman, Inc.

Cabot Corporation

Cameca Instruments, Inc

CEMCOM Research Associates

CILAS Alcatel

Combustion Engineering, Inc.-Power Systems

Denton vacuum, Inc.

Drytek, Inc.

E. I. du Pont de Nemours \& Company

Dynavac

Eastman Kodak Company

Eaton Corporation

ELKEM Chemicals, Inc.

Elsevier North-Holland

Energy Conversion Devices, Inc.

Engelhard Corporation

Charles Evans \& Associates

Exxon Research and Engineering Company

Ferranti, plc

GCA Corporation

General Electric Ceramics, Inc.

General Electric Company

General Ionex Corporation

General Motors Research Laboratories

GTE Laboratories

Harshaw/Filtrol

Helionetics

High Voltage Engineering Europa B.V.

Hirst Research centre

Hitachi Scientific Instruments

Hoya Optics, Inc.

Hughes Aircraft Company

Imperial Chemical Industries, plc

Instruments SA Inc.

International Business Machines Corporation

JEOL USA

Jet Propulsion Laboratory
Lam Research

Lambda Physik

Lanxide Corporation

Lasertechnics

Lawrence Livermore National Laboratory

Leybold-Heraeus

LFE Corporation

Los Alamos National Laboratory

Lumonics

3M company

Martin Marietta Laboratories

Materials Research Corporation

Microscience, Inc.

Monsanto

National Electrostatics Corporation

Newport Corporation

Perkin-Elmer

Philips Electronic Instruments, Inc.

Plasma Technology (UK) Ltd.

Plasma-Therm Systems, Inc.

Portland Cement Association

Quantronix Corporation

Questek, Inc.

Rockwell International

Sandia National Laboratories

Schlumberger-Doll Research

Schott Glass Technologies, Inc.

SEH America, Inc.

L. M. Simard, Inc.

SOHIO Chemicals \& Industrial Products Solar Energy Research Institute

Solarex

spire Corporation

Standard Oil of Indiana

Stauffer Chemical company Surface Science Laboratories, Inc.

Tamarack Scientific Co.

Tegal Corporation

TRW

Union Carbide Corporation

United Technologies Research Center

UOP

Varian/Extrion

VC Instruments, Inc.

W. R. Grace \& Company

Wacker Siltronic Corporation

Westinghouse Electric Corporation

xerox Corporation

$X M R$

zymet 

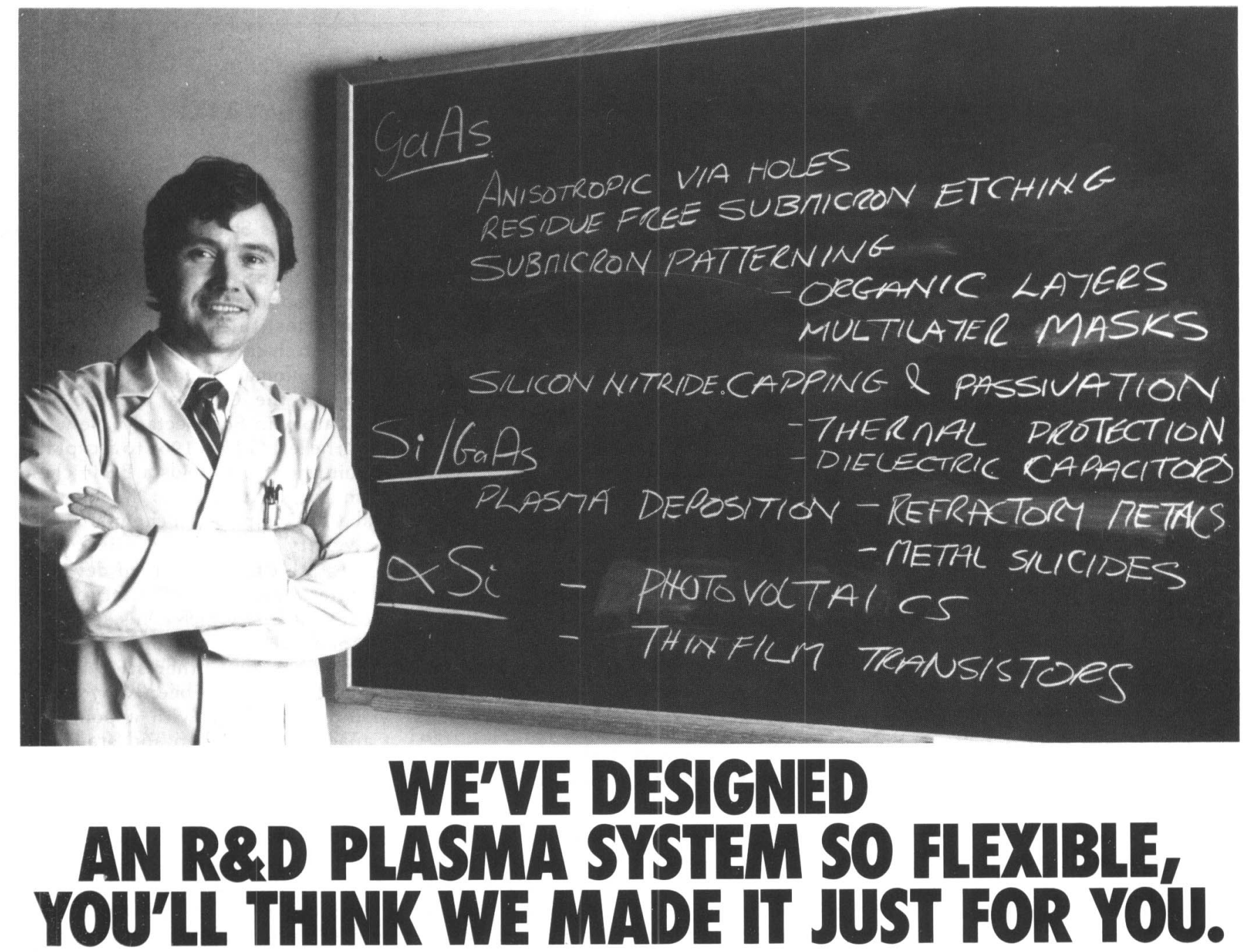

It is called the Plasmalab 80 and consists of a range of modules which allow you to design an REDD system that does exactly what you want it to do; no more, no less. Plasmalab can be configured for all of the principle plasma processes-Planar Etch, RIE, Planar Deposition or Plasma Anodisation. A basic Plasmalab may consist of only a single work chamber and flow controller; however, because Plasmalab is modular, you can

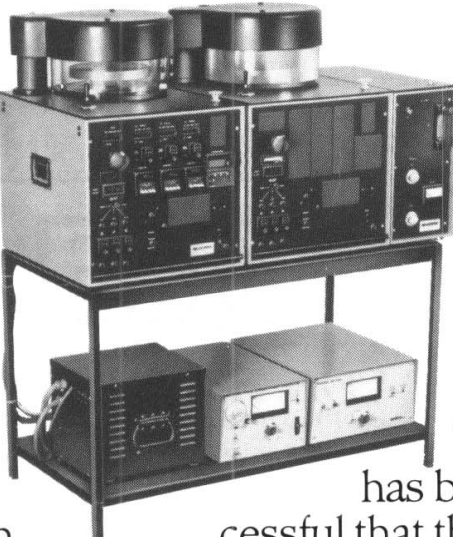

cessful that there are already 140 installations in use worldwide pioneering new processes in silicon and GaAs technology. (The inset shows a 2 um $\mathrm{x}$ 2um Reactive Ion Etched structure in $\mathrm{GaAs}^{*}$ ). Plasmalabs are available worldwide through the offices and agents of Plasma Technology Ltd. chamber from one process to another. 